\title{
Early Satiety Is the Only Patient-Reported Symptom Associated With Delayed Gastric Emptying, as Assessed by Breath-Test
}

\author{
Yishai Ron, ${ }^{1}$ Ami D Sperber, ${ }^{1}$ Arie Levine, ${ }^{2}$ Orit Shevah, ${ }^{3}$ Ram Dickman, ${ }^{4 *}$ Yona Avni ${ }^{3}$ and Haim Shirin ${ }^{4}$ \\ ${ }^{1}$ Department of Gastroenterology and Hepatology, Sourasky Medical Center, Tel-Aviv, Israel, ${ }^{2}$ Pediatric Gastroenterology Unit and \\ ${ }^{3}$ Gastroenterology Unit, The Edith Wolfson Medical Center, Holon, Israel, ${ }^{4}$ Division of Gastroenterology, Rabin Medical Center, Tel-Aviv \\ University, Petach Tikva, Istael
}

\section{Background/Aims}

To evaluate associations between delayed gastric emptying (GE) assessed by the octanoic acid breath test and upper gastrointestinal (GI) symptoms.

\section{Methods}

A historical, prospective study included 111 consecutive symptomatic adults referred for a GE breath test because of upper abdominal symptoms suggestive of delayed GE. Exclusion criteria included underlying organic disease associated with delayed GE. Patients completed a symptom questionnaire and underwent a GE octanoic breath test. Patients with delayed GE were compared with those with normal results, for upper Gl symptoms.

\section{Results}

Early satiety was the only symptom significantly associated with delayed GE. It was observed in $52 \%$ of subjects with delayed GE compared to $33 \%$ patients with no evidence of delayed GE $(P=0.005)$. This association was seen for all degrees of severity of delayed GE. Patients with early satiety had a $t_{1 / 2}$ of $153.9 \pm 84.6$ minutes compared to $110.9 \pm 47.6$ minutes in subjects without it $(P=0.002)$. In a logistic regression model, early satiety was significantly associated with delayed GE (OR, 2.29; $95 \% \mathrm{Cl}, 1.01-5.18 ; P=0.048)$.

\section{Conclusions}

Early satiety is the only patient-reported GI symptom associated with delayed GE. The utility of GE tests as a clinical diagnostic tool in the work-up of dyspeptic symptoms may be overrated.

\section{(J Neurogastroenterol Motil 2011;17:61-66)}

Key Words

Breath tests; Dyspepsia; Gastric emptying

Received: October 5, 2010 Revised: December 20, 2010 Accepted: December 21, 2010

(c) This is an Open Access article distributed under the terms of the Creative Commons Attribution Non-Commercial License (http://creativecommons. org/licenses/by-nc/3.0) which permits unrestricted non-commercial use, distribution, and reproduction in any medium, provided the original work is properly cited.

*Correspondence: Ram Dickman, MD

Division of Gastroenterology, Rabin Medical Center, Beilinson Hospital, 100 Zabotinski St, Petach Tikva 49100, Israel

Financial support: None.

Tel: +972-3-9377236, Fax: +972-3-9210313,E-mail: dickmanr@clalit.org.il

Conflicts of interest: None. 


\section{Introduction}

Delayed gastric emptying (GE) is associated with a wide spectrum of gastrointestinal (GI) symptoms, in particular post prandial fullness/early satiety, nausea and vomiting. ${ }^{1}$ Although several studies have reported an association between delayed gastric emptying and clinical symtoms, ${ }^{2,3}$ others have not found support for this association. ${ }^{4,5} \mathrm{~A}$ recent study in patients with delayed GE did not find an association between GE and GI symptoms, except for symptoms that were associated with proximal stomach dysfunction. ${ }^{6}$ It is noteworthy that rapid GE may also result in nausea, bloating and epigastric fullness, making the clinical dignosis of delayed gastric emptying problematic. ${ }^{7}$

Thus, symptoms of delayed GE are nonspecific and may overlap with other GI disorders including functional dyspepsia, peptic ulcer disease or gastric malignancy. ${ }^{8}$ Moreover, in some prokinetic drug trials, there has been a poor correlation between medical facilitation of GE and symptom improvement, suggesting that delayed GE was not the cause of the symptoms. In addition, no dose dependent effect was seen, ie, between increasing severity of GE delay and symptom severity. ${ }^{9,10}$

Several mechanisms have been proposed to explain the clinical manifestation of delayed GE, including antral hypomotility, impaired gastric accommodation, ${ }^{11}$ visceral hypersensitivity, absence of the interstitial cells of $\mathrm{Cajal}^{12}$ and gastric dysrhythmias. These putative mechanisms are controversial, because a moderate delay of GE in healthy individuals is not associated with an increase in meal-related symptoms. ${ }^{13}$

Ghoos et $\mathrm{al}^{14}$ were the first to show the benefit of measuring the GE rate of solids by a non-invasive octanoic acid breath test. Although GE scintigraphy of a solid-phase meal is considered the gold standard for the diagnosis of delayed GE, ${ }^{15}$ the octanoic acid breath test provides reproducible results that correlate with GE scintigraphy. ${ }^{14,16,17}$ The primary aim of the present study was to further characterize associations between upper GI symptoms and delayed GE as assessed by patient reports of symptoms and results of the octanoic acid breath test. An additional objective was to look at possible associations between the severity of GE delay (classified as mild, moderate and severe) and upper GI symptoms.

\section{Materials and Methods}

The E. Wolfson Medical center serves as a secondary and tertiary referral center. This study was approved by the hospital's institutional review board. Each patient gave written informed consent.

This was a historical, prospective study of 111 consecutive adults, aged 18 to 79 years, who were referred for a GE breath test because of upper abdominal symptoms suggestive of delayed GE. Only patients fullfilling the Rome II criteria for functional dyspepsia and failed empirical medical therapy were included. Patients were excluded at entry if they had a peptic ulcer, an organic disease associated with delayed GE such as diabetes mellitus, Parkinson's disease, cerebrovascular accident, neuromuscular disease, eating disorder, gastrostomy tube, gastric outlet obstruction, history of gastric surgery, fundoplication or treatment with anticholinergic or antidepressants drugs.

Endoscopic criteria for exclusion were esophagitis of over grade 2 by Savary-Miller classification or all types of Los Angeles classification. Patients with diaphragmatic hernia of larger than 3 $\mathrm{cm}$ or erosive gastritis were excluded. Medical treatment was prescribed for all patients with pathologic findings and the GE tests were conducted between 2 weeks to 3 months after cessation of treatment only in those patients who did not respond to medical therapy.

As detailed below, the study participants completed a sociodemographic and symptom questionnaire and underwent a GE breath test. Helicobacter pylori (H. pylori) status was determined by endoscopic biopsy (CUTest, Temmler Pharma, Marburg, Germany) or urea breath test.

The questionnaire included socio-demographic data, a review of medical history, and the section of the official Rome II questionnaire on upper GI symptoms, with particular emphasis on relation to nausea and vomiting, post-prandial fullness, early satiety and bloating. Only patients with frequent symptoms of at least $25 \%$ of time were included in the study.

\section{Gastric Emptying Breath Tests}

GE was evaluated using the previously validated ${ }^{13} \mathrm{C}$-labelled octanoic acid 4 hour breath test (BreathID, Exalenz, Jerusalem, Israel). ${ }^{17}$ All breath tests were performed in the morning, over a 4-hour period in a sitting position after an overnight fast. Proton pump inhibitors were discontinued at least 1 week prior to evaluation of $\mathrm{GE}$.

The BreathID collected breath samples continuously from patients who were connected to the instrument through a nasal canula based circuit. The instrument analyzed breath samples before and after ${ }^{13} \mathrm{C}$ enriched octanoic acid administration. The 
BreathID system utilized $100 \mathrm{mg}{ }^{13} \mathrm{C}$-labelled octanoic acid dissolved in a standard sized scrambled egg with 2 slices of bread, which provide $250 \mathrm{kcal}$, as the test meal. Based on Molecular Correlation Spectrometry, the BreathID continuously measured ${ }^{13} \mathrm{CO}_{2}$ and ${ }^{12} \mathrm{CO}_{2}$ concentrations from the patient's breath and established the ${ }^{13} \mathrm{CO}_{2} /{ }^{12} \mathrm{CO}_{2}$ ratio, which was displayed vs time on the screen. The ${ }^{13} \mathrm{CO}_{2} /{ }^{12} \mathrm{CO}_{2}$ ratio was normalized for patient's weight, height and ${ }^{13} \mathrm{C}$ substrate and dose. This provided percentage dose recovery and cumulative percentage dose recovery and calculated the $\mathrm{t}_{1 / 2}$, tlag and the gastric emptying coefficient (GEC, data not presented in this article). These calculations were based on analyses using a non-linear model, as described by Ghoos et al. ${ }^{14}$ The results have been printed on a thermal printer and saved to a hard disk.

Based on Ghoos et al, ${ }^{14}$ the normal ranges for the GE parameters were defined as $\mathrm{t}_{1 / 2}$ 50-94 minutes, tlag 12-52 minutes and GEC 2.95-3.55 (delayed emptying < 2.95). Based on the $t_{1 / 2}$ values and as we could not find any severity index in assessment of delayed GE time in the literature, we divided our patients into 4 groups: normal emptying, 50-94 minutes; mild delay, 95-199 minutes (up to 2 times of upper normal limit); moderate delay, 200-299 minutes (up to 3 times of upper normal limit); and severe delay, $\geq 300$ minutes (over 3 times of upper normal limit).

In order to evalute the association between GI symtoms and delayed GE, patients with delayed GE were compared to a group without delayed GE and a dose effect was sought for individual symptoms.

\section{Statistical Methods}

Data were analyzed using the SPSS 9.0 statistical analysis software (SPSS Inc, Chicago, IL, USA). For continuous variables descriptive statistics were calculated and were reported as mean $\pm \mathrm{SD}$. Normality of distribution was assessed using the Kolmogorov-Smirnov test (cut-off at $P=0.01$ ). All continuous variables had approximately normal distributions permitting the use of parametric methods. The $t$ test for independent samples was used to compare continuous variables between subjects with and without delayed GE. One way analysis of variance was used to compare continuous variables across breath test categories. Pearson's correlation coefficient was calculated to describe associations between continuous variables.

Categorical variables are presented as frequency (\%). The $\chi^{2}$ test (exact test when indicated) was used to assess associations between delayed GE and symptoms, gender and breath test categories. All tests were 2 -sided and statistical significance was set at
$P<0.05$.

\section{Results}

The study population was comprised of 111 consecutive patients referred for a GE breath test because of upper abdominal dyspeptic symptoms suggestive of delayed GE. There were $76 \mathrm{fe-}$ males (mean age $42 \pm 16$ years) and 35 males (mean age $43 \pm$ 16 years). According to the Rome II criteria for functional dyspepsia, there were 36 patients with ulcer like dyspepsia, 63 with dysmotility like dyspepsia and 13 with unspecified dyspepsia.

\section{Gastric Emptying Tests}

The results of the GE breath tests showed that 48 patients had no evidence of delayed GE (Group 1), while 63 (Group 2) had evidence for it. There was no difference between the groups in terms of age or body mass index (Table 1). Looking at the data from all patients (Groups 1 and 2), epigastric bloating was reported by 67 patients $(60.4 \%)$, post-prandial nausea or vomiting by $60(54.1 \%)$ and early satiety by $49(44.1 \%)$. A significant, positive correlation was observed between the number of symptoms and the $t_{1 / 2}$ result $(r=0.217, P=0.026)$ in Group 2 with the delayed GE. However, there was no significant association between GE and symptoms of abdominal pain, nausea, vomiting, bloating, heartburn and hiccups. There was also no significant association between these symptoms and the severity of delayed GE. The only symptom that was significantly associated with delayed GE was early satiety, which was reported by $33 \%$ in Group 1 and $52 \%$ in Group $2(P=0.005)$ (Table 1$)$. The mean $\mathrm{t}_{1 / 2}$ was $153.9 \pm 84.6$ minutes in subjects with early satiety vs $110.9 \pm$ 47.6 minutes in subjects without it $(P=0.002)$. In a logistic regression model, early satiety was significantly associated with delayed GE (OR, 2.29; 95\% CI, 1.01-5.18; $P=0.048)$. Early satiety increases the odds of mild degree of delayed $\mathrm{GE}$ by a factor of 2.5 (OR, 2.5; 95\% CI, 1.1-5.6; $P=0.024$ ) and of moderate to severe degree of delayed GE by a factor of more than 6 (OR, 6.2; 95\% CI, 1.6-23.7; $P=0.003$ ). All subjects with severe degree of delayed GE had early satiety (OR, 1.2; 95\% CI, 1.041.33; $P=0.003)$. There was no significant correlation between early satiety and tlag and GEC.

\section{Helicobacter pylori and Delayed Gastric Empty- ing}

There was no significant association between delayed GE and $H$. pylori status. Of 80 patients who were tested for $H$. pylori 
Table 1. Comparison of the Age, Gender, Body Mass Index, Clinical Symptoms and Helicobacter pylori Status Between Group 1 and 2

\begin{tabular}{|c|c|c|c|c|c|c|}
\hline & \multirow{2}{*}{$\begin{array}{l}\text { Group } 1 \\
(\mathrm{n}=48)\end{array}$} & \multicolumn{4}{|c|}{ Group 2} & \multirow{2}{*}{$P$-value } \\
\hline & & Mild $(n=46)$ & Moderate $(\mathrm{n}=9)$ & Severe $(\mathrm{n}=8)$ & All $(\mathrm{n}=63)$ & \\
\hline Age $($ mean $\pm \mathrm{SD})$ & $43.6 \pm 15.8$ & $41.4 \pm 17.8$ & $42.2 \pm 17.7$ & $44.4 \pm 18.6$ & $42 \pm 17.5$ & NS \\
\hline Gender (male/female) & $13 / 35$ & $16 / 30$ & $5 / 4$ & $1 / 7$ & $22 / 41$ & NS \\
\hline $\mathrm{BMI}\left(\right.$ mean $\left.\pm \mathrm{SD}\left[\mathrm{kg} / \mathrm{m}^{2}\right]\right)$ & $24.7 \pm 4.8$ & $23.3 \pm 4.5$ & $27.0 \pm 6.5$ & $24.6 \pm 4.8$ & $24 \pm 5$ & NS \\
\hline Abdominal pain & $33(68.8)$ & $24(52.2)$ & $7(77.8)$ & $6(75.0)$ & $37(58.8)$ & NS \\
\hline Bloating & $27(56.3)$ & $27(58.6)$ & $5(55.6)$ & $8(100.0)$ & $40(63.5)$ & NS \\
\hline Nausea & $21(43.8)$ & $20(43.5)$ & $5(55.6)$ & $6(75.0)$ & $31(49.2)$ & NS \\
\hline Vomiting & $9(18.8)$ & $16(34.8)$ & $4(44.5)$ & $1(12.5)$ & $21(33.3)$ & NS \\
\hline Heartburn & $21(43.8)$ & $18(39.1)$ & $2(22.3)$ & $3(37.5)$ & $23(36.5)$ & NS \\
\hline Hiccups & $8(16.7)$ & $6(13.0)$ & $3(33.3)$ & $3(37.5)$ & $12(19.0)$ & NS \\
\hline Early satiety & $16(33.4)$ & $20(43.5)$ & $5(55.6)$ & $8(100.0)$ & $33(52.4)$ & 0.002 \\
\hline H. pylori & $10(20.1)$ & $5(10.8)$ & 0 & 0 & $5(7.9)$ & NS \\
\hline
\end{tabular}

H. pylori, Helicobacter pylori.

Data are presented as $\mathrm{n}(\%)$ unless otherwise stated.

Table 2. Comparison of the Endoscopic Findings Between the Control and Delayed Gastric Emptying Group

\begin{tabular}{|c|c|c|c|c|c|c|}
\hline & \multirow{2}{*}{$\begin{array}{l}\text { Group } 1 \\
(\mathrm{n}=37)\end{array}$} & \multicolumn{4}{|c|}{ Group 2} & \multirow{2}{*}{$P$-value } \\
\hline & & Mild $(\mathrm{n}=35)$ & Moderate $(n=7)$ & Severe $(n=5)$ & All $(n=47)$ & \\
\hline Normal & $26(70.3)$ & $21(60.0)$ & $6(85.7)$ & $3(60.0)$ & $30(63.8)$ & NS \\
\hline Esophagitis & $6(16.2)$ & $3(8.6)$ & 0 & $1(20.0)$ & $4(8.5)$ & NS \\
\hline Hiatal hernia & $3(8.1)$ & $6(17.1)$ & 0 & 0 & $6(12.7)$ & NS \\
\hline Duodenitis & $1(2.7)$ & $4(11.4)$ & 0 & 0 & $4(8.5)$ & NS \\
\hline Food remnants & $3(8.1)$ & $3(8.6)$ & $1(14.3)$ & $1(20.0)$ & $5(10.6)$ & NS \\
\hline
\end{tabular}

Group 1, control group; Group 2, delayed gastric emptying group.

Some patients had more than 1 finding. None of the differences was statistically significant. Data are presented as n (\%).

by urea breath test or by CUTest, 15 were positive, $10(21 \%)$ in Group 1 and 5 (11\%) in Group 2 (Table 1).

\section{Endoscopic Findings and $t_{1 / 2}$, tlag or Gastric Emptying Coefficient}

Eighty-four patients underwent esophagogastroduodenoscopy prior the GE test. The distribution of endoscopic findings are presented in Table 2. None of the endoscopic findings was associated with $\mathrm{t}_{1 / 2}$, tlag or GEC.

\section{Discussion}

Delayed GE has been associated with various GI symptoms. An evaluation of GE is often performed when no other rational explanation is found for persistent symptoms. Identifying the presence of delayed GE may enable physicians to establish a final diagnosis in patients with vexing symptoms and no other clear explanation. $^{18}$

The results of this study indicate that the majority of GI symptoms leading to the performance of a GE test are not associated with delayed GE. Early satiety was the only symptom that was found to have a significant association with delayed GE. The association with early satiety was demonstrated in mild, moderate and severe degree of GE delay. Early satiety increases the odds of mild degree of delayed GE by a factor of 2.5 and of moderate to severe degree of delayed GE by a factor of more than 6. All subjects with severe degree of delayed GE had early satiety (OR, 1.2). There was no association between early satiety and the other 2 measured parameters of GE, tlag or GEC. Our results confirmed the previous findings of Stanghellini and Sarnelli. ${ }^{2,3,19}$ However, they also found an association between delayed GE and nausea and vomiting, which was not seen in the present study. Sarnelli et $\mathrm{al}^{2}$ reported a significant association between delayed solid or liquid GE and postprandial fullness and vomiting. 
Vomiting is a non-specific symptom that may be induced by other etiologies such as regurgitation associated with gastroesophageal reflux disease or rumination. ${ }^{20,21}$ The prevalence of delayed GE among gastroesophageal reflux disease patients ranges from $10 \%$ $41 \% .^{21,22}$ Delayed GE may be a proxy for other disorders that lead to vomiting and early satiety. Karamanolis et $\mathrm{al}^{6}$ recently demonstrated that many of the symptoms previously associated with delayed GE are actually due to fundic dysmotility.

Another factor that may have impact on delayed GE is $H$. pylori. This hypothesis is based on theoretical grounds as well as epidemiologic and clinical studies. ${ }^{23} H$. pylori has been found to be inversely correlated with the prevalence of delayed GE and certain studies have shown improvement of GE with eradication. ${ }^{24}$ We failed to demonstrate an association between $H$. pylori status and delayed GE and confirmed the previous reports of no association between delayed GE and H. pylori. ${ }^{25,26}$ Moreover, since the prevalence of $H$. pylori in our country is high, we would expect to see an aggravation of delayed GE symptoms if there actually is an association between them.

The major drawback of this study is the arbitrary setting of severity of GE delay to 3 groups of mild (up to twice normal GE time), moderate (up to 3 times normal GE time) and severe (over 3 times normal GE time). This setting is due to the fact that there is no valid data from the literature we could rely on. Future research is essential in grading the severity of delayed GE and comparison with symptom frequency and severity.

In conclusion, we found that among all the patient with reported symptoms, early satiety was the only symptom that was associated with delayed GE regardless of its severity. These findings suggest that the utility of GE tests as a clinical diagnostic tool in the work-up of upper GI symptoms suggestive of delayed GE may be overrated.

\section{References}

1. Soykan I, Sivri B, Sarosiek I, Kiernan B, McCallum RW. Demography, clinical characteristics, psychological and abuse profiles, treatment, and long-term follow-up of patients with gastroparesis. Dig Dis Sci 1998;43:2398-2404.

2. Sarnelli G, Caenepeel P, Geypens B, Janssens J, Tack J. Symptoms associated with impaired gastric emptying of solids and liquids in functional dyspepsia. Am J Gastroenterol 2003;98:783-788.

3. Stanghellini V, Tosetti C, Paternico A, et al. Risk indicators of delayed gastric emptying of solids in patients with functional dyspepsia. Gastroenterology 1996;110:1036-1042.

4. Scott AM, Kellow JE, Shuter B, et al. Intragastric distribution and gastric emptying of solids and liquids in functional dyspepsia. Lack of influence of symptom subgroups and $H$. pylori-associated gastritis. Dig Dis Sci 1993;38:2247-2254.

5. Talley NJ, Shuter B, McCrudden G, Jones M, Hoschl R, Piper DW. Lack of association between gastric emptying of solids and symptoms in nonulcer dyspepsia. J Clin Gastroenterol 1989;11:625630.

6. Karamanolis G, Caenepeel P, Arts J, Tack J. Determinants of symptom pattern in idiopathic severely delayed gastric emptying: Gastric emptying rate or proximal stomach dysfunction? Gut 2007;56:29-36.

7. Delgado-Aros S, Camilleri M, Cremonini F, Ferber I, Stephens D, Burton DD. Contributions of gastric volumes and gastric emptying to meal size and postmeal symptoms in functional dyspepsia. Gastroenterology 2004;127:1685-1694.

8. Maes BD, Ghoos YF, Hiele MI, Rutgeerts PJ. Gastric emptying rate of solids in patients with nonulcer dyspepsia. Dig Dis Sci 1997; 42:1158-1162.

9. Jones KL, Russo A, Stevens JE, Wishart JM, Berry MK, Horowitz M. Predictors of delayed gastric emptying in diabetes. Diabetes Care 2001;24:1264-1269.

10. Keshavarzian A, Iber FL, Vaeth J. Gastric emptying in patients with insulin-requiring diabetes mellitus. Am J Gastroenterol 1987;82:2935.

11. Kindt S, Tack J. Impaired gastric accommodation and its role in dyspepsia. Gut 2006;55:1685-1691.

12. Forster J, Damjanov I, Lin Z, Sarosiek I, Wetzel P, McCallum RW. Absence of the interstitial cells of Cajal in patients with gastroparesis and correlation with clinical findings. J Gastrointest Surg 2005;9: 102-108.

13. Tack J, Coulie B, Verbeke K, Janssens J. Influence of delaying gastric emptying on meal-related symptoms in healthy subjects. Aliment Pharmacol Ther 2006;24:1045-1050.

14. Ghoos YF, Maes BD, Geypens BJ, et al. Measurement of gastric emptying rate of solids by means of a carbon-labeled octanoic acid breath test. Gastroenterology 1993;104:1640-1647.

15. Horowitz M, Fraser RJ. Gastroparesis: diagnosis and management. Scand J Gastroenterol 1995;213(suppl):7-16.

16. Bromer MQ, Kantor SB, Wagner DA, Knight LC, Maurer AH, Parkman HP. Simultaneous measurement of gastric emptying with a simple muffin meal using [13C]octanoate breath test and scintigraphy in normal subjects and patients with dyspeptic symptoms. Dig Dis Sci 2002;47:1657-1663.

17. Dickman R, Steinmetz A, Bernnstine H, Groshar D, Niv Y. A novel continuous breath test versus scintigraphy for gastric emptying rate measurement. J Clin Gastroenterol 2011;45:22-25.

18. Parkman HP, Hasler WL, Fisher RS. American Gastroenterological Association technical review on the diagnosis and treatment of gastroparesis. Gastroenterology 2004;127:1592-1622.

19. Cassilly DW, Wang YR, Friedenberg FK, Nelson DB, Maurer AH, Parkman HP. Symptoms of gastroparesis: use of the gastroparesis cardinal symptom index in symptomatic patients referred for gastric emptying scintigraphy. Digestion 2008;78:144-151.

20. O'Brien MD, Bruce BK, Camilleri M. The rumination syndrome: Clinical features rather than manometric diagnosis. Gastroenterology 1995;108:1024-1029.

21. McCallum RW, Berkowitz DM, Lerner E. Gastric emptying in patients with gastroesophageal reflux. Gastroenterology 1981;80:285- 
291.

22. Keshavarzian A, Bushnell DL, Sontag S, Yegelwel EJ, Smid K. Gastric emptying in patients with severe reflux esophagitis. Am J Gastroenterol 1991;86:738-742.

23. Fock KM, Khoo TK, Chia KS, Sim CS. Helicobacter pylori infection and gastric emptying of indigestible solids in patients with dysmotility-like dyspepsia. Scand J Gastroenterol 1997;32:676-680.

24. Miyaji H, Azuma T, Ito S, et al. The effect of Helicobacter pylori eradication therapy on gastric antral myoelectrical activity and gastric emptying in patients with non-ulcer dyspepsia. Aliment Pharmacol Ther
1999;13:1473-1480.

25. Caballero-Plasencia AM, Muros-Navarro MC, Martin-Ruiz JL, et al. Dyspeptic symptoms and gastric emptying of solids in patients with functional dyspepsia. Role of Helicobacter pylori infection. Scand J Gastroenterol 1995;30:745-751.

26. Chang CS, Chen GH, Kao CH, Wang SJ, Peng SN, Huang CK. The effect of Helicobacter pylori infection on gastric emptying of digestible and indigestible solids in patients with nonulcer dyspepsia. Am J Gastroenterol 1996;91:474-479. 